\title{
TACTILE PERCEPTUAL RIVALRY AND TACTILE-AMORPHOSYNTHESIS IN THE LOCALIZATION OF CEREBRAL LESIONS

\author{
With special reference to parietal lobes
}

\author{
By S. Fazlullah, M.B.(Osm.), D.T.M. \& H. \\ Late Senior House Physician, Lowestoft and North Suffolk Hospital; late Medical Registrar, Barrow and Furness \\ Group of Hospitals, Lancs.; Medical Registrar, Pontefract and Castleford Group of Hospitals, Yorks.
}

\section{Introduction}

Recently attention of neurologists has been directed to the clinical value of using bilateral simultaneous and ipsilateral double stimuli in testing cutaneous sensations. If two similar stimuli are applied simultaneously on the two sides of the body, eyes being closed, the patient announces that he feels the object only on the unaffected side. When each side is tested separately, the object is readily appreciated correctly. This sensory suppression phenomenon on the affected side is termed as tactile-amorphosynthesis (inattention or extinction). This phenomenon is not rare and is frequently observed in parietal lesions.

Oppenheim (I885, I9II) first described this method of testing in a lady of 74 years with right hemiplegia and termed it as 'double stimulation.' Head and Holmes (r9II) observed this phenomenon in cortical disorder by using weight in two hands simultaneously, so that when asked, the patient described the one in the normal hand. Since then several others have observed this phenomenon. Bender (1945) observed this phenomenon in parietal lobe lesion on the hemiplegic side and termed as extinction. Since then, he has demonstrated it in patients with cerebrovascular accidents, affecting other portions of the cerebral hemisphere, diffuse brain lesions, and lesions of other parts of the central nervous system. Critchley (1949), in his masterly review on this phenomenon, suggested a self-explanatory term, ' tactile inattention.' Recently Brain (1955) termed this sensory suppression as 'perceptual rivalry' which is more informative about its nature. At present, there is no general agreement about the nature of this sensory defect and terminology.

\section{Material}

The purpose of the present study was to deter- mine the incidence of extinction or inattention phenomena in patients with space occupying? lesions and other lesions in various parts of the central nervous system. The observations were recorded in 38 cases, diagnosis being made as a result of careful histories, physical examinations,,$\circ$ confirmed by special investigations, operative and post-mortem findings.

\section{Procedure}

Each patient was blindfolded and tested for $\vec{\varphi}$ extinction:

(a) By application of simultaneous stimuli wi cotton wool, pin prick, vibration, and thermal contacts, (i) on homologous areas of face, shoulders, wrists, hips and feet, (ii) on heterologous areas: left wrist and right foot, right wrist and $\propto$ left foot, (iii) on two areas of the same side of the $\overrightarrow{\vec{O}}$ body: face and shoulder, shoulder and hand, face 3 and hand, shoulder and hip, and hip and foot. Patients were instructed to report on the location? of the stimulus and its nature. Stereognostic음 methods were also used: two similar objects were placed in patient's hands simultaneously and the $\frac{5}{3}$ patient was asked to report on the size, shape and nature of the object. Figures were also drawn 의 simultaneously on the two sides of the body and the patient was asked to report on their identi- $\frac{}{3}$ fication. Even the cruder stimuli such as rub- $\frac{D}{O}$ bing, scratching, and seizure of the patient's two hands simultaneously may be used to demon- $N$ strate this phenomenon.

(b) By salt and sugar being applied simul- N taneously on the two sides of the tongue. The patient was asked to rinse the mouth with water and report on the location and nature of the taste. Somesthetic sensations were tested by pin prick and touch applied simultaneously on the ${ }^{+}$ two sides of the tongue. Tactile and painful $\frac{0}{\circ}$ bilateral simultaneous stimuli were also applied $\vec{\Phi}$ 
on the left side of the tongue and the right side of the face, the right side of the tongue and the left side of the face, to note extinction of the face or the tongue stimulus.

\section{Results}

\section{Extinction or Tactile Perceptual Rivalry}

(a) Well defined extinction. Six cases with deep and ten of extensive parietal lesions exhibited constant and well defined extinction or tactile inattention with the parietal lobe syndromes, according to the involvement of the dominant (left) or the subordinate (right) cerebral hemisphere. Out of the 23 parietal lobe disease cases examined, 2 I showed extinction or tactile inattention; I4 cases manifested well defined and constant extinction with the right parietal lobe syndromes.

(b) Incomplete extinction. Four cases of parietal lesions showed incomplete extinction, i.e. stimulus on the abnormal side was dull, delayed, felt imperfectly, inconstantly and incorrectly localized. In such cases the extinction was best demonstrated by astereognosis when the size, shape, weight and physical property of the stimulus was not recognized correctly on the abnormal side. The palm writing method was useful in such cases. Inconstant (incomplete) extinction was observed in the superficial or less extensive lesions.

(c) Ipsilateral extinction. On application of two ipsilateral simultaneous stimuli, one on the face and the other on the hand, the stimulus on the distal segment was suppressed. This suppression was noted in the four cases of parietal lesions with cortical sensory loss, i.e. hemianaesthesia, astereognosis, two-point discriminative loss, ataxia, graphaesthesia and postural defect. This ipsilateral extinction was observed also infrequently, in lesions of the mid-brain and spinal cord (Table 2). In one case of spinal cord glioma (astrocytoma G II), two stimuli were applied simultaneously, one on the face and the other below the supposed level of the lesion. This lower area previously had been found to be sensitive to some degree on single stimulus, the patient feeling the upper stimulus only. Additional trials were made, stimulating simultaneously the same facial area and successively more rostral portions of the lower area, so that the level of the lesion was approached by the lower stimulus, at which the patient felt the lower stimulus equal to the upper one in intensity. Shapiro and Feldman (1952) termed this level as the 'level of double simultaneous stimulation.' This level in this patient coincided with the anatomical level, confirmed by myelography and operative findings. Recently Shapiro and Feldman (1952) demon- strated the 'double simultaneous stimulation level ' in 50 cases of spinal cord disease.

(d) No extinction. Extinction was not observed in two cases with superficial parietal lesions (parietal lobe meningioma and angioma). In the early stage of parietal tumours, especially when superficial or benign, even in the presence of sensory loss, tactile inattention or extinction is not observed. In the case with parietal meningioma, presenting with Jacksonian fits in left foot with left-sided ataxia, neither sensory loss nor extinction was present on the left side. The case of angioma (parietal) presented with subarachnoid haemorrhage. Cases with strict frontal, temporal lesions and raised intracranial pressure showed no extinction. One case of deep frontotemporo-parietal glioblastoma exhibited extinction in association with right parietal and frontal lobe syndromes. Bender states that the two stimuli should be equal in intensity. In cases of deep parietal lesions with marked extinction, this precaution is not necessary. A powerful pin prick, on the abnormal side, is suppressed by a light touch on the normal side. Dissimilar stimuli, such as cotton wool, on the healthy side, can suppress pin prick on the affected side. If the stimulus is very strong and maintained more than three seconds, the single sensation may give way slowly to double. In cases with a superficial parietal lesion showing less defined or incomplete extinction, the two stimuli should be equal in intensity and nature, i.e. cotton-cotton or pin prick-pin prick. In cases of deep parietal lesions this precaution is not essential.

\section{Extinction of InatTention oR Tactile AMORPHOSYNTHESIS}

Extinction is abolished temporarily if the eyes are opened, patient's attention is directed towards the affected side, repeated stimuli are applied and pressure continued for a long time. This phenomenon was not observed in well defined extinction with deep parietal neoplasm, encroaching on the thalamus, or extensive and rapidly destructive parietal lesions when attention does not play any part in suppression of inattention.

\section{Displacement Phenomenon (Tactile Alloaesthesia)}

Patients with extinction, also, showed displacement phenomenon. When a stimulus was applied on the affected side it was felt at a distant point, on the same side or on the opposite side of the proximal mirror image point of the body, i.e. a stimulus from the foot is felt at the thigh or hip, that from the hand at the shoulder. In such cases, it may be assumed that the stimulus, by blocking thalamo-cortical impulses at the primary 
zones of sensation, has moved to the secondary zones of sensation with the predominant homolateral representation. Extinction may be a form of tactile alloaesthesia.

\section{Disorder of MOTILITY}

Catatonia without grasp reflex was observed in eight cases of parietal lesions (deep glioblastoma five, secondaries two, cortical atrophy one). One case of a biparietal vascular lesion exhibited an unusual phenomenon: on stimulation of the left sole the left plantar reflex was extensor and at the same time the right plantar reflex was extensor as well (crossed plantar extensor). On stimulation of the right sole the right plantar reflex was flexor, whilst on application of simultaneous stimuli to both soles the left was extensor and the right was flexor (extinction of the crossed plantar extensor). Cohn (1948) described extinction of the Babinski sign on bilateral simultaneous stroking of the soles, the extensor reflex on the contralateral side of the parietal lesion was extinguished. This extinction of the crossed plantar extensor phenomenon has not been described before. This phenomenon was observed constantly for four weeks only, then it regressed. This sign is analogous to 'Rothfield manoeuvre' (1932), i.e. passive straight leg raising on one side is said to provoke a contralateral associated flexion movement in presence of either contralateral frontal or ipsilateral parieto-temporal lesion. This sign with the other ones enables the clinician to localize the lesion.

\section{Unilateral Extinction or Perceptual Rivalry with Rostrocaudal Dominance}

All cases with ipsilateral extinction also exhibited rostrocaudal dominance, i.e. if two stimuli were applied on one side of the body the proximal suppresses the distal one. The face was constantly dominant over the shoulder, wrist, hip and foot. In no case did the lower stimulus extinguish the perception of that applied on the face. This fact reveals the dominance of the face over the rest of the body (Bender, I95I ; Cohn, I95 I ; and Critchley, 1949).

Extinction of Taste and Somesthetic Sensations on Bilateral Simultaneous Stimuli (on tongue and face)

Börstein (1940) observed sensory defect for touch, pain and taste in his three cases of parietal lobe injury. He inferred that the cortical representation of taste is near the parietal lobe operculum and that it is related more closely to the face and mouth area than to the olfaction area. Bender and Daniel (1952) observed extinction of taste and somesthetic sensation in parietal lobe lesions. Six cases with well defined extinctior tion of taste, painful and tactile stimuli. Extinctio was observed on the sensory deficit side an sometimes displacement to the other side was observed, the significance of which is not known In two cases of deep right parietal glioblastoma,. on bilateral simultaneous stimulation of tw $\vec{F}$ sides on the tongue, the left stimulus was extin? guished. Simultaneous stimuli (touch or pig prick) on the right side of the face and the lef: side of the tongue, extinguished the left-side tongue stimulus. Tactile or painful stimulio applied to the right side of the tongue and the left side of the face, extinguished the left-face stimuli.

\section{Other Findings}

In the patients showing extinction corticas sensory loss was observed as astereognosis, ataxia loss of two-point discrimination, paraesthesia and hemianaesthesia. In four cases astereognosis onl bु was observed. Visual field changes were observe@्巳 as follows:

(a) Homonymous hemianopia (six cases) witb right parietal syndrome.

(b) Balint's optic agnosia (two cases).

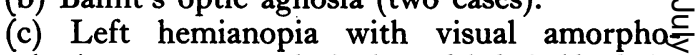
synthesis or perceptual rivalry of left half of the space (two cases).

\section{Parietal Lobe Syndromes}

Right parietal lobe syndromes were observed four cases of deep neoplasm (two encroaching or the thalamus) and in eleven cases with diffuse or localized cortical lesions (vascular 5, cortica atrophy $\mathrm{I}$, head injury $\mathrm{I}$, secondaries 3 , angioma $\mathrm{I}) \stackrel{\overrightarrow{\mathrm{O}}}{\mathrm{C}}$

(a) Left Parietal Syndrome. The following signs were noted in four cases of left parieta vascular lesions:

(I) Gertsman syndrome.-Finger agnosia (mistake in recognition of finger). Right and left dis orientation (unable to differentiate right and left) $\frac{0}{3}$ Agraphia (mistakes in writing). Dyscalculia (mis takes in calculation). Nominal aphasia (mistakes in naming things). We know this syndrome manifests after lesions of 'angular gyrus' on the left side.

(2) Parietal apraxia.-The patients exhibiting this apraxia have lost their ability to understand the idea of the action or to execute the actions, though there is no paralysis of the limbs. This apraxip is produced by disruption of supra-marginal angular gyri with the motor cortex via the callosa body. Hence a callosal or supra-marginal-gyte lesion can produce the same type of apraxia.

(3) Construction apraxia.-In cases with left parieto-occipital lesions this apraxia is manifested as disturbances in drawing, especially of geo $\vec{D}$ 
metrical figures. In trying to copy the models, the patient draws a meaningless confusion of lines. Gross construction apraxia was noted in drawing from memory. This apraxia results due to incoordination between motor, visual and sensory cortex. The temporal qualities are also disrupted with the other cortices.

(b) Right Parietal Syndrome. Among the syndromes the following were noted:

(I) Anosognosia.- The patient cannot perceive the defective function such as hemiplegia. Five cases with vascular lesions denied the existence of hemiplegia on the left side.

(2) Hemiasomatognosia.-The patient is unable to focus attention on the paretic side and states that the paretic half of the body is strange. Eight cases of right parietal lesions showed this syndrome.

(3) Metamorphognosia.-The patient feels that a portion of the body is heavy and thick.

(4) Corporeal agnosia.-The patient feels that sensation of half of the body or the extremity is lost.

(5) Phantom sensations. - The patient feels that a portion of the body has doubled. Six cases of deep parietal neoplasm, one case of cortical atrophy and five cases of vascular lesion complained that their left arm was heavy, thick, funny and did not belong to them.

(6) Transposition of parts of the body.-The patient feels that a part of the body is transferred to another part or beyond the body. One of the cases of biparietal vascular lesion was asked to show his left hand; he started searching for his left arm everywhere in the bed, then he opened the locker to see if his left hand was there. When he was asked to do anything with the left hand he always did it with the right, neglecting the left side of the body. Three cases with deep parietal neoplasm, two cases with secondaries, and one case with cortical atrophy also exhibited this phenomenon.

(7) Construction apraxia.-This was noted in 14 cases of right parietal lesions. This apraxia is an important and common event in cases of parietal disease. It is essentially an executive defect within the visuo-spatial domain and is associated with other spatial disorders and visual disorientation. It is an interference with the formative activity (arranging, drawing, copying models) and disorder of the spatial part of the task. Patients with right parietal disease, when asked to copy models or draw maps of things seen before illness, make meaningless confusions and mistakes in construction of one-two-three dimensional figures. Drawings show splitting of details with simultaneous neglect of left side of the objects. Ordinarily at the bedside this defect can be demonstrated by the use of matchsticks and the use of paper-and-pencil tests. There is enough clinical evidence that this defect is a result of inco-ordination between motor, sensory, visual and temporal cortical function.

(8) Disorientation of space.-The patients were unable to recognize depth of the space. One case complained that the windows and walls were inclining towards her. She exhibited biparietal syndrome with opticagnosia, due to cerebral embolism.

(9) Agnosia of left portion of space.-The patients were unable to perceive sensation coming from the left portion of the space (visual-auditory and extra-personal stimuli). Six cases had homonymous hemianopia, another two had no homonymous visual field defect but still they neglected the left half of the space and body. One case of right parietal angioma and another of vascular lesion complained, ' if the bus is on my left side I will walk into it, and I am unable to read words and lines on the left side of the newspapers since my illness.' In this type of visual agnosia the patient is unable to perceive visual stimuli coming from the left portion of the space. Denny Brown (1953) explained this syndrome as a visual amorphosynthesis of spatial stimuli or visual perceptual rivalry.

(I0) Anaesthoagnosia.-In six cases with deep parietal lesions there was profound sensory loss of the left half of the body with anosognosia and disorder of the left half of the body awareness. Pötzl (1924) believes that a lesion of the thalamus is significant in the production of this syndrome. In this series two cases with deep parietal glioblastoma encroaching on the postero-lateral thalamus exhibited sensory loss and body awareness disturbances on the affected side. One of such cases had painful syndrome but no thalamic dyaesthesia.

(I I) Balint optic ataxia.-Balint (I909) first described this syndrome which he called 'psychic paralysis of visual fixation' in which disturbance of visual fixation is associated with optic ataxia and visual inattention. These patients are unable to see two things at the same time. They are unable to co-ordinate voluntary ocular movements in response to sudden visual stimuli. There is visual inattention for the objects. The patients are unable to see the object in the left peripheral field. Most prominent visual stimuli (those falling on the macula) actually reach consciousness, the others at the periphery are not seen.

Gordon Holmes (1918) described this syndrome in bilateral parietal or angular-supramarginal gyri lesions. Two cases of cerebral embolism with bilateral parietal syndrome exhibited this visual phenomenon. They were unable to see in the left half of the peripheral field, revealed by the 
Table I.-Localization of Lesion with Extinction

\begin{tabular}{|c|c|c|c|}
\hline Nature of lesion & Site of lesion & $\begin{array}{l}\text { No. of } \\
\text { cases }\end{array}$ & Parietal syndrome \\
\hline Glioblastoma & $\begin{array}{l}\text { Deep R. temporo- } \\
\text { parietal }\end{array}$ & 3 & $\begin{array}{l}\text { R. parietal syndrome: Anosog- } \\
\text { nosia; body image disorder on } \\
\text { L. half of body; construction } \\
\text { apraxia; neglect of L. half of } \\
\text { body }\end{array}$ \\
\hline Secondaries & $\begin{array}{l}\text { Deep R. temporo- } \\
\text { parietal }\end{array}$ & 3 & do. $\quad \cdot$ \\
\hline Cortical atrophy & R. & I & do. \\
\hline Glioblastoma & $\begin{array}{l}\text { R. deep fronto- } \\
\text { temporo-parietal }\end{array}$ & I & $\begin{array}{l}\text { Frontal and R. parietal syndrome } \\
\text { (body image disorder) }\end{array}$ \\
\hline Vascular Lesions & & & \\
\hline (a) Thrombosis & L. parietal & 2 & $\begin{array}{l}\text { L. parietal syndrome (Gertsman } \\
\text { syndrome, colour agnosia, per- } \\
\text { severation of visual agnosia) }\end{array}$ \\
\hline (b) Embolism & R. parietal & 5 & $\begin{array}{l}\text { R. parietal syndrome: Anosog- } \\
\text { nosia; body image disorder; } \\
\text { neglect of } L \text {. side; } R \text {. and } L \text {. } \\
\text { parietal syndromes in } 2 \text { cases; } \\
\text { construction apraxia }\end{array}$ \\
\hline $\begin{array}{l}\text { Head injuries } \\
\quad \text { (closed) }\end{array}$ & R. parietal & 3 & $\begin{array}{l}\text { R. parietal syndrome in I case; } \\
\text { nil in } 2\end{array}$ \\
\hline Angioma & R. parietal & $\mathbf{I}$ & $\begin{array}{l}\text { R. parietal syndrome: Construc- } \\
\text { tion apraxia; agnosia of } \mathrm{L} \text {. half } \\
\text { of the space }\end{array}$ \\
\hline
\end{tabular}

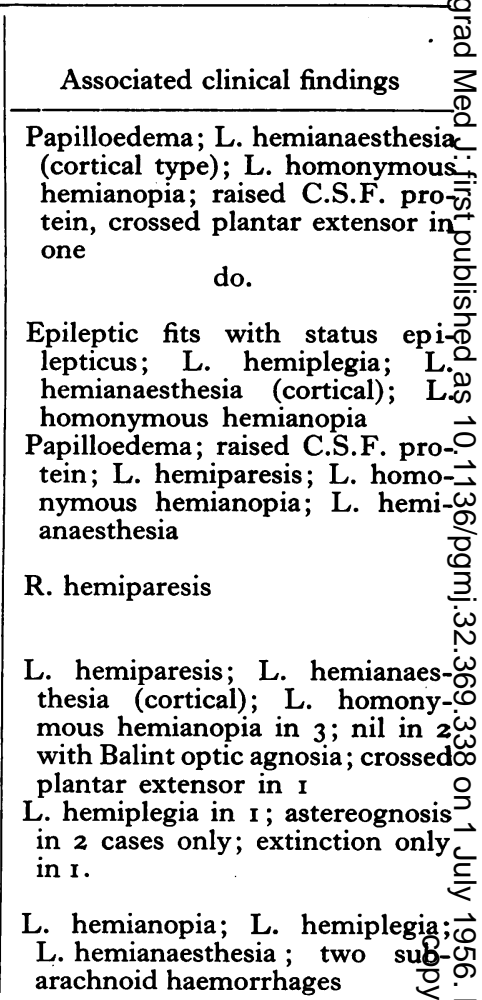
arachnoid haemorrhages

three-flower test; they missed the flower in the left peripheral field and recognized the right and middle one. There was no fundal change or acuity of vision defect. They complained that they could not see two things shown simultaneously in the left half of their visual field and used to miss objects, words and lines of sentences on the left side while reading newspapers. In counting lines, they could count one or two and would neglect other lines further on the left. As soon as the object left the central field there was great difficulty in localizing it. There was a complete inability to to estimate the distance between two objects. In lighting a cigarette, the patient found difficulty in touching the end of it with the flame and said: 'I can see only one at a time.' This defect of vision was seen more frequently in the left peripheral field than in the right.

In reality this visual agnosia is a special disturbance in conception or amorphosynthesis of spatial stimuli, hence it can be called visualamorphosynthesis or visual perceptual rivalry.

\section{Parietal Pain Syndrome (pseudo-thalamic syndrome)}

One case, who had two attacks of subarachnoid haemorrhage, used to get frequent fainting attacks and tinnitus, developed electric shock-like pain ơ⿱ the right half of the body without thalamic dysaesthesia. She exhibited ataxia, astereognosis $\frac{\%}{\varnothing}$ and hemianaesthesia on the right half of the body. The clinical features suggest that the pain is of $\overrightarrow{\overrightarrow{0}}$ central origin rather than thalamic, in view of the 3 absence of over-reaction to stimuli. This fact? suggests inhibition of thalamus by the parietal $\stackrel{-}{-}$ lobe via parieto-thalamic fibres, the release of $\frac{0}{3}$ which results in the painful syndrome.

\section{Discussion}

It has been thought that 'extinction' was a specific sign of parietal lobe disease. This sign 0 is observed frequently in parietal lobe disease as shown in the Tables $I$ and 2 . Infrequently this sign is observed in lesions of the sensory tracts in other regions, such as the spinal cord and brain os stem, as is shown in two cases of brain stem and N in one of spinal cord glioma, which gives a clinical N proof of the existence of a separate parieto-tectum $\sigma$ and parieto-spinal projections, apart from parietothalamic connections. Peele (1942), in a most $\frac{0}{\varnothing}$ searching study on the important and complex parietal projections, found that each parietal lobe 0 gives rise to association fibres to other parietal $\bar{O}^{\circ}$ areas and projection fibres not only to the thalamus 
Table 2.-Localization of Lesion with Ipsilateral Extinction

\begin{tabular}{|c|c|c|c|c|}
\hline Nature of lesion & Site of lesion & $\begin{array}{l}\text { No. of } \\
\text { cases }\end{array}$ & Parietal syndrome & Associated clinical findings \\
\hline Glioma & L. parietal & $\mathbf{I}$ & - & $\begin{array}{l}\text { R. hemiparesis; R. hemianaes- } \\
\text { thesia; R. ataxia; R. astereog- } \\
\text { nosis; C.S.F. protein }++\end{array}$ \\
\hline Angioma & L. parietal & I & - & $\begin{array}{l}\text { Two attacks of subarachnoid } \\
\text { haemorrhage; frequent fainting } \\
\text { attacks; R. ptosis; sensory loss } \\
R \text {. half of body with pseudo- } \\
\text { thalamic syndrome; R. ataxia; } \\
\text { R.-sided astereognosis }\end{array}$ \\
\hline Glioma & L. parietal & I & - & $\begin{array}{l}\text { Eplipetic fits; R. ptosis; R. di- } \\
\text { plopia; R. side ataxia; parietal } \\
\text { hemianaesthesia on R. half of } \\
\text { face and arms; C.S.F. pro- } \\
\text { tein }++\end{array}$ \\
\hline Angioma & Mid-brain & 1 & - & $\begin{array}{l}\text { Transient faints, since } 7 \text { years; } \\
\text { vertigo; dysphagia; slurred } \\
\text { speech; L. V lesion; R. VI } \\
\text { lesion; L. VII lesion (upper } \\
\text { motor neuron); R. hemianaes- } \\
\text { thesia; R. hemiparesis; recurrent } \\
\text { trigeminal neuralgia }\end{array}$ \\
\hline Glioma & Mid-brain & I & - & $\begin{array}{l}\text { L. hemianaesthesia; L.L. VII } \\
\text { lesion (upper motor neuron); } \\
\text { L. VIII lesion; nystagmus; } \\
\text { ataxia on L.; defective upward } \\
\text { conjugate deviation; C.S.F. pro- } \\
\text { tein raised }\end{array}$ \\
\hline Astrocytoma & $\begin{array}{l}\text { L. cerebello- } \\
\text { pontine angle }\end{array}$ & I & - & $\begin{array}{l}\text { L. hemiparesis; L. ataxia (cere- } \\
\text { bellar) nystagnus; L. V, VI, } \\
\text { VIII lesions }\end{array}$ \\
\hline Secondaries & $\begin{array}{l}\text { L. cerebellum with } \\
\text { brain stem dis- }\end{array}$ & I & 一 & $\begin{array}{l}\text { Vertigo; L. hemiparesis; L. as- } \\
\text { tereognosis }\end{array}$ \\
\hline Astrocytoma & Spinal cord & I & - & $\begin{array}{l}\text { Radicular pain R. leg; spastic } \\
\text { monplegia } R \text {. leg with patchy } \\
\text { sensory loss up to L4; C.S.F. = } \\
\text { zanthoschromia }\end{array}$ \\
\hline
\end{tabular}

(pulvinar and postero-lateral parts) but also to the mid-brain, medulla, pons and spinal cord. The parietal lobe is represented in the pulvinar and in postero-lateral part of the thalamus.

Ipsilateral extinction (unilateral extinction) in this series was observed in superficial benign parietal lesions, such as angioma, glioma, localized head injury and vascular lesions which permit greater adaptation of cerebral functions. Perhaps, in such cases, large numbers of thalamo-parietal fibres are spared from damage.

Constant and well defined extinction was observed in cases with deep parietal neoplasm, encroaching on the thalamus, widespread and rapidly destructive cerebral lesions. Parietal lobe syndromes were associated with well defined extinction in cases with deep parietal neoplasm and rapidly destructive lesions or diffuse cerebral lesions. It is noteworthy that extinction phenomenon is not universally demonstrable in parietal disease. Two cases of proved parietal neoplasm (meningioma, angioma) did not show extinction. In superficial lesions, perhaps, very few thalamo-parietal projection fibres are involved, therefore no sensory defect occurs.

It is interesting to note that extinction phenomenon is usually found in patients with evidence of cortical sensory deficit and anosognosia; it is not always present in such cases, and it also occurs in the absence of such deficit. In five cases of parietal lesions there was no sensory loss, but extinction was observed.

All the patients with extinction phenomena also showed face dominance and ipsilateral extinction when two simultaneous stimuli were applied on two areas on the same side of the body. Raised intracranial pressure had no influence on extinction.

Face stimulus extinguished the opposite tongue stimulus and similarly tongue stimulus extinguished opposite face stimulus. This fact shows that the face and the tongue areas are close together in the parietal lobe.

Bender (1949) recently found that light pressure stimulus elicits extinction better in several patients than painful stimulus, and also emphasized the 
Table 3.-Localization of Lesion with No Extinction

\begin{tabular}{|c|c|c|c|c|}
\hline Nature of lesion & Site of lesion & $\begin{array}{l}\text { No. of } \\
\text { cases }\end{array}$ & Parietal syndrome & Associated clinical findings $\frac{\bar{\varrho}}{2}$ \\
\hline $\begin{array}{l}\text { Angioma } \\
\text { Meningioma }\end{array}$ & $\begin{array}{l}\text { R. parietal lobe } \\
\text { R. parietal lobe }\end{array}$ & $\begin{array}{l}\text { I } \\
\text { I }\end{array}$ & 二 & $\begin{array}{l}\text { Subarachnoid haemorrhage } \\
\text { Jacksonian fits in the L. foot } \\
\text { L. hemiparesis (marked L.L.) } \\
\text { L. ataxia: paraesthesia L foot }\end{array}$ \\
\hline $\begin{array}{l}\text { Secondaries } \\
\text { Meningioma } \\
\text { Compound }\end{array}$ & $\begin{array}{l}\text { Frontal lobe } \\
\text { Frontal lobe }\end{array}$ & $\begin{array}{l}\mathbf{I} \\
\mathbf{I}\end{array}$ & $\begin{array}{l}\text { Frontal-lobe syndrome } \\
\text { Frontal-lobe syndrome }\end{array}$ & Loss of smell; C.S.F. protein $+\frac{\overline{0}}{10}$ \\
\hline $\begin{array}{l}\text { fracture } \\
\text { Porencephaly }\end{array}$ & Frontal area & I & - & Temnoral enilengr. \\
\hline Abscess & Temporal & $3^{*}$ & - & $\begin{array}{l}\text { háemorrhage } \\
\text { Chronic ear infection; status epi } \\
\text { lepticus in } \mathrm{I} \text {; meningitis in } \\
\text { C.S.F. }+++ \text { (sterile pus) }\end{array}$ \\
\hline Neuroma & R. 8th nerve & I & - & $\begin{array}{l}\text { Headache; blindness; papilloe } \\
\text { dema; nerve deafness; raise } \\
\text { intracranial pressure }\end{array}$ \\
\hline $\begin{array}{l}\text { Cerebral } \\
\text { embolism }\end{array}$ & R. cerebral & 2 & - & L. hemiparesis \\
\hline
\end{tabular}

* Bilateral I, unilateral 2

value of testing extinction on non-homologous areas as well. Ziegler (1952) observed well defined or constant extinction in deep parietal lesions and inconstant extinction in superficial lesions. In the presented material six cases of deep parietal neoplasm and 12 diffuse parietal lesions showed well defined extinction. Three patients with the superficial parietal lesions exhibited less defined extinction and the two other cases showed no extinction.

\section{Mechanism of Extinction}

Some authorities have tried to explain extinction phenomena physiologically (Bender, 1945; and Denny Brown, 1953). Critchley (1949, 1953) believes that this is neither a physiological nor psychological problem but is a defect in the local attention, because it is broken down by opening the eyes and by repeated testing, hence he coined a new self-explanatory term ' tactile inattention.' Bender states that attention plays no part, repeated testing, varying the type and area of stimulus, are the essentials for the elicitation of ' extinction.'

Attention does play a part in incomplete extinction with less damage to parietal lobes. But in cases of deep-seated neoplasm, encroaching on the thalamus or massive rapidly destructive lesions, attention does not play any part in extinction of inattention. This suggests that the thalamus and its peduncle are significant, where thalamo-cortical fibres are packed together. At present we know nothing about the physiological basis of attention.

Head and Holmes (I9II) emphasized that localized defect of 'attention' is the basis of many characteristic sensory defects, seen in parietal lesion. Critchley (1949, 1953) believes that 'expectant attention' is not directed to the् affected side in parietal lesion. They claim thato the sensory cortex is the site for ' attention' and all the complex manifestations of awareness, hencea parietal lesion gives rise to disturbances in loca $E$ attention, in body scheme and in awareness of body unity.

\section{Morphosynthesis}

Denny Brown (1953) emphasized that the summation of spatial stimuli, under the term of ' morphosynthesis,' are part of the functions of parietal lobes. Amorphosynthesis, conceptual and perceptual defects explains the extinction phe- $\overrightarrow{0}$ nomena, and many other sensory defects produced $B$ by parietal lesions. It is justifiable to call parietal sensory defect as tactile or visual amorphosynthesis.

\section{Perceptual Rivalry}

Critchley (1949) and Denny Brown (1953) believe that there is a ' rivalry' between the two stimuli at the highest cortical sensory level. That one on the sensory deficit side is suppressed and? fails to attain consciousness, the loss of one stimulus leads to over-activity of the other and thus 'perceptual rivalry' results in inconstancyos in all types of defects and also explains " extinction "N phenomena and many other parietal defects. Theñ term tactile or visual perceptual rivalry is more ${ }_{\sigma}^{\omega}$ informative and self-explanatory than tactile or visual inattention.

\section{The Role of Thalamus and Callosal Body in Body Unity}

Chang, experimentally, and Pötzl, clinically, 
came to the conclusion that there is an intimate link between the callosal functions and the functions of the thalamo-cortical system. Cortical potentials can be observed by the stimulation of the corporis callosum. In accordance with the anatomical investigations of Chang, the anterior part of the callosum contains fibres from the anterior brain, the posterior part from the posterior brain, and the central part from the temporal and parietal brain. Callosal fibres are dense in the posterior part (fibres from the posterior parietal lobe). It is probable that this part is responsible for the formation of a whole 'body sensation scheme' without a mid-line in our mind. According to Hoff and Pötzl there is swinging of impulses between two hemispheres via the callosal body. They believe that there is a middle line in the thalamus dividing the body in two parts. Sensory and kinaesthetic impulses, if they pass over the middle line of the thalamus, inhibit stimuli of homolateral side and stimuli of the contra-lateral side are accentuated. In the thalamus, sensations are localized on the contra-lateral side but due to the interlaminary nuclei of the thalamus, the sensations of half of the body are combined in one, hence normally we do not feel a middle line.

Cortical functions modify this unity, being accentuated in the optic and acoustic field, hence a thalamic or parietal lesion can produce this body unity defect.

Two cases of deep temporo-parietal glioblastoma, encroaching on the postero-lateral part of the thalamus and the posterior part of the callosal body, exhibited gross body unity disturbance with right parietal syndromes and well defined extinction. These two cases present a clinical proof of the importance of postero-lateral part of the thalamus and posterior callosal body in the formation of body unity.

Henson (I949) described a case of deep right parieto-occipital glioblastoma with gross destruction of the pulvinar of thalamus, exhibiting body unity disturbances, extinction and thalamic dysaesthesia which was suppressed by simultaneous bilateral stimulation. Attention played no part in extinction of tactile inattention. In the presented material two cases with deep parietal neoplasm and six cases of extensive parietal lesions exhibited body unity disorders and sensory changes on the affected side, but there was no extinction of inattention when patient's attention was directed to the affected part. This fact again emphasizes the importance of the thalamus and its peduncle in the production of parietal sensory defects.

\section{Cortical versus Subcortical Lesions}

Small parietal lesions will probably produce different clinical effects eccording to whether they involve the cortex, lie immediately deep to the cortex and between the cortex and thalamus, or actually invade the thalamic nuclear mechanism, in addition to ascending and descending thalamoparietal pathways.

In this series two cases with localized superficial parietal neoplasms (meningioma and angioma), showed neither extinction nor parietal syndrome, while one head injury case had extinction with right parietal syndrome, and two others with head injuries had no parietal syndrome except extinction. Four cases with deep localized parietal neoplasm and ten cases of extensive parietal lesion (cortical atrophy I, secondaries 2, and vascular lesions 7) produced manifold parietal syndromes, Two parietal cases who had localized deep glioblastoma, encroaching on the postero-lateral part of the thalamus, produced the same picture as that produced by the diffuse parietal lesions. This fact suggests that destruction of the posterolateral thalamus or its peduncle, extensive lesions of thalamo-parietal fibres, damage to angularsupramarginal gyri and calloso-commissural fibres, result in parietal syndromes due to disruption of the sensory cortex with the temporal, occipital and motor cortices.

\section{Mechanism of Parietal Lobe Syndromes}

Le Gros Clark and Boggon (1935) believe that the thalamo-cortical fibres system is more complex in man and there must be an intermingling of the complex corticofugal fibres, cortico-cortical association fibres and commissural tracts. Two cases of localized deep glioblastoma, involving the thalamic peduncle, give a clinical proof of this fact. They exhibited gross sensory loss and various parietal syndromes.

In two cases of superficial parietal neoplasm (meningioma and angioma) and five other cases of benign superficial lesions with some cortical sensory loss such as astereognosis, ataxia, hemianaesthesia, extinction and graphaesthesia, no parietal syndromes were observed. It is most likely that, in these cases, thalamo-cortical and other association fibres are not involved extensively, some fibres such as thalamo-marginalangular gyri being spared.

These clinico-pathological observations may suggest that parietal lobes, due to their central position in the brain, have the function of combining and concentrating as well as dividing the occipital, temporal, sensory cortex with the motor cortex; suppressing the disturbing impulses, facilitating the useful ones, and fixing them in distinct parts of the brain. Complex mental tasks, of high intellectual order, require harmonious integration of manifold impulses and disruption of which leads to various syndromes, as released 
phenomena or due to amorphosynthesis of stimuli and perceptual rivalry.

Critchley (1953) believes that it is illogical to conclude that these activities are part of parietal function; for probably these are activities of the brain as a whole, integration of temporal, occipital and sensory cortices may be concerned in threedimensional spatial quality, interconnection of vision and mobility is necessary for three-dimensional construction. The parietal lobe, by combining all these qualities, builds up the body scheme and corporeal awareness. Topographical memory requires integration of manifold impulses.

Recently Hoff (1953), using vector electroencephalography, obtained a distinct picture from left parieto-occipital lesions. He tried to prove the functional difference between the two parietal lobes with inconclusive results. $\mathrm{He}$ obtained parieto-occipital alpha rhythm of higher voltage which was more pronounced on the right than the left. Beta waves are more prevalent on the left. Alpha spindles occur on both sides. He suggested that in pathological disorder of the left parietal lobe, the lesion causes misdirection of impulses, flowing out from the left into different regions. Various previously used schemes overlap the misdirected schemes, and result in various types of apraxia.

Hans Hoff (1953) believes that the two parietal lobes have an important co-function in combining frontal, temporal and occipital impulses. At the same time each prevents disturbing impulses and concentrates as well as divides occipital, temporal and central functions. The right parietal, connecting our sensation. with total function of the brain, forms the body unity. The left parietal lobe has the function of highest sensory level such as calculation, speech, reading and writing, disruption of which leads to various parietal defects.

Extensive disorder of function may result in body image disorder, which is built up of past and present visual, auditory, tactile, postural and sensory perception. Lesions, in the deep parietal lobe, cause corporeal agnosia by interfering with synthesis of cutaneous and proprioceptive impulses with other sensory data. Widespread and bilateral parietal lesions result in visual agnosia due to interference of connection between visual and other association areas. Diffuse cerebral lesions of the left parietal or left angular gyrus result in apraxia of idea. Disruption of parietal (L) or L-angular gyrus with the motor cortex causes ideomotor apraxia. Constructional apraxia results from disturbances of visual-spatial functions with kinaesthetic impulses. Probably, temporal quality also combines with it. Parietal ataxia results by interference of parieto-cerebellar connections. Parietal-ataxia and hypotonia mag. be due to disruption of parieto-cerebellar con nections.

In conclusion, it can be said that the effects of lesions of the parietal lobes, as described above? are not limited to parietal lobes, but are also followed by entire malfunction of the brain, du할 to distortion of these combining impulses of amorphosynthesis of the sensory stimuli, contoceptual and perceptual defects.

\section{Summary}

Twenty-three cases of parietal lesions arê described:

(I) 'Extinction' or 'tactile amorphosynthesis' was observed in the 21 parietal lesions. Extincs tion is the specific sign of the parietal disease and should be tested routinely.

(2) Well defined extinction was observed i cases of deep parietal lesions, encroaching on th thalamus or thalamic peduncle and in extensive oळ rapid destruction of parietal lobes. In such cases extinction was associated with parietal syndromes్రా The superficial, benign, and less extensive lesiong showed inconstant extinction without parietal syndromes.

(3) Mechanisms of extinction and parietal lobe syndromes have been discussed.

\section{Acknowledgment}

I wish to record my thanks to the physiciand for providing facilities for the study of these cases, particularly Dr. K. A. Latter (Consulting Physician and Neurologist, Norfolk and Norwic Hospital), Dr. W. H. Palmer (Physician, Lowestof Hospital), Dr. A. P. B. Waind (Consulting Physio cian, Barrow and Furness Group of Hospitals) Dr. J. K. Slater (Consultant Neurologist, Roy高 Infirmary, Edinburgh) for his critical review on the paper, the Neurosurgical Department of Queen Square National Hospital, London, and Man: chester for arranging angiography, etc., an supplying reports on the operative findings, Dir J. E. Horrocks (Consultant Pathologist, Barrow and Furness Group of Hospitals) for the pathoo logical reports and helpful advice in the prepara tion of the paper, and Dr. L. Watson (Consultanto Pontefract and Castleford Group of Hospitals) fo his helpful suggestions.

\section{BIBLIOGRAPHY}

BALINT, R. (1909), Mschr. Psychiat. Neurol., 25, 5 I.

BENDER, M. B. (1945), Arch. Neurol. Psychiat., 54, I-9. BENDER, M. B. (1948), M. Clin. North America, 32, 755.

BENDER, M. B., and DANIELS, S. F. (1952), Neurology, 195-202.

BENDER, M. B. (195I), Arch. Neurol. \& Psychiat., 66, 355-758. BORSTEIN, W. S. (1940), Yale F. Biol. E' Med., 12, 719.

BORSTEIN, W. S. (1940), Ibid., 13, 133.

Bibliography continued on page 352 
Dr. Lumb: Could I just clarify one point for myself here? In interpreting the flocculation tests is it true to say that any one of them may be raised in different cases ?

Professor Maclagan: Yes, but those which most commonly show gross abnormality are the zinc and ammonium sulphate tests.

Professor Pulvertaft: So far we have discussed tumour deposits in bone only. In what other organs have you personally found deposits ?

DR. LUMB: In a few cases one has seen plasma cell proliferations in liver and spleen and lymph nodes. In other words when the proliferations become generalized they tend to involve the reticuloendothelial system. It is my own personal view that these conditions are in fact a tumour of the reticuloendothelial system most commonly

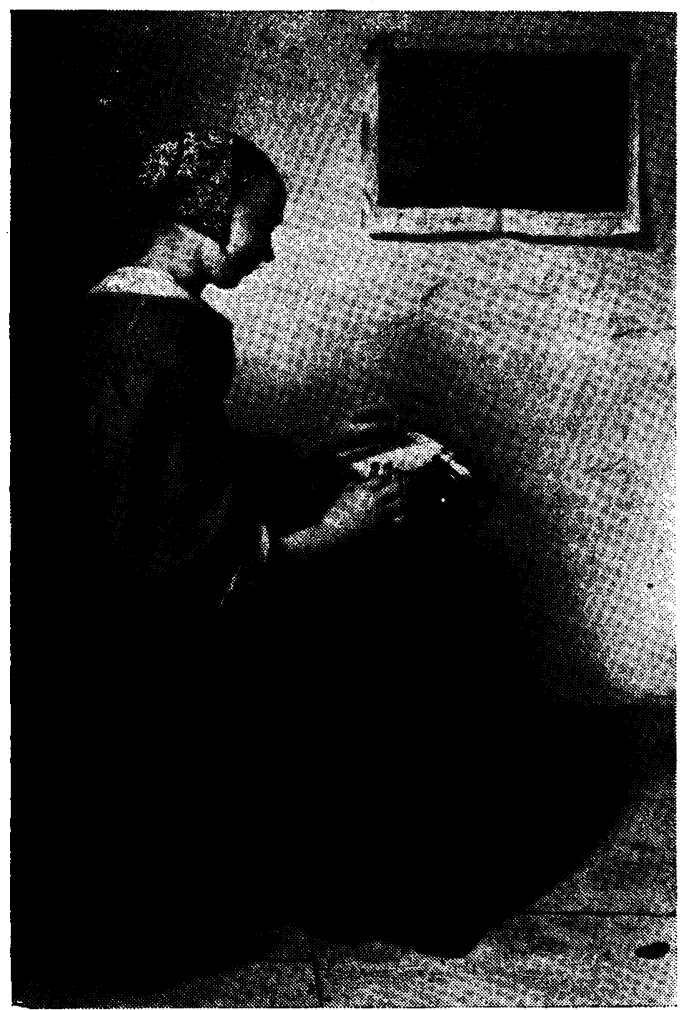

\section{Restoration of Repose}

\section{with}

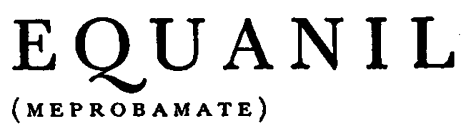

an outstanding new drug to lessen tension,

reduce irritability and restlessness, and to

produce more restful sleep and

generalized muscular relaxation.

Supplies:

Bottles of 20 and $250 \times 400$ mgm.tablets

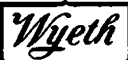

The word 'Equanil' is a registered trade mark

JOHN WYETH \& BROTHER LIMITED

Clifton House, Euston Road, London, N W I localized in bone. Occasionally, as you know, examples of plasma cell leukaemia are found.

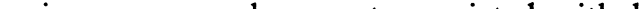

\section{BIBLIOGRAPHY}

CHVIL, C. H., and REIF, A. E. (r955), . Biol. Chem., 2I6, I03.

GRIFFITHS, L. L., and BREWS, V. A. L. (1953), F. Clin. Path., MAN, A. B., MOORE, D. H., GUTMAN, E. B., McCLELLAN, V., and KABAT, E. A. (I941), F. Clin. Invest., MORISON, J. E., F. Path. Bact., 53, 403

TNAM, F. W., and HARDY, S. (I955), F. Biol. Chem., 212 , TH, E. S., BROWN, D. M., McFADDEN, M. L., BUETTNER-JANUSCH, V., and JAGER, B. V. (1955), Ibid., 216, 601.

Reproduced by permission of the Trustees of the $W$ allace $C$ nllection

Bibliography continued from page 346.

S. Fazlullah, M.B.(

BRAIN, R., and STRAUSS, E. B. (1955), Rec. Adv. Neurol. Psychiat., 44-54.

CHANG HSIANG-TUNG (1953), f. Neuro. Physiol., 16, 177.

CLARK, W. E. LEGROS, and BOGGON, R. H. (1935), Phil. Trans., 224B, 313.

COHN, R. (1948), F. Neurol Physiol., I1, 193-197.

COHN, R. (1951), Neurology, r, 119.

COHN, R. (1951), F. Neur. E' Ment. Dis., 113, 47 I.

CRITCHLEY, M. (1951), Proc. Roy. Soc. Med., 44, 337.

CRITCHLEY, M. (1953), Fifth Int. Neurol. Conference, $153-167$.

CRITCHLEY, M. (I953), ' Parietal Lobes,' Arnold \& Co., London, $144,203,225,256,326,356$.

CRITCHLEY, M. (I949), Brain, 1xxii, 538-56r.

DENNY-BROWN, D. (1953), Fifth Int. Neurol. Conference, pp. 215-216.

(1949), Brain, 1xxii, 576, 598

HEAD H, and HOLMES, G. (1911), Brain, 34, 102-254.

HOLMES, G. (1918), British 7 . Ophthalmology, 2.

OPPENHEIM, H. (1885), Neurol. Centralb., 4, 529-532.

OPPENHEIM, H. (1911), Textbook of Nervous Diseases, $1,5 \mathbf{r}$. Fifth Edition. Trans., A. Bruce Edinburgh and T. N. Foulis. PEELE, T. L. (1942), Four. Comp. Neurol., 77, 693.

POTZL, O. (1924), Ztschr.f. d. ges. Neuro . u. Psych., 93. POTZL, O. (I953), referred by H. Hoff.

ROTHFIELD, J. (I932), Nervenartz, 5, 528-532.

SHAPIRO, M. F., and DANIELS, F. (1952), Neurology, 2, 509-51 3 ZIEGLER, D. K. (1952), Ibid., 2, $501-508$. 